\title{
Más allá del Estado. Perspectivas y lineamientos para su estudio y definición
}

\author{
Paula Mussetta*
}

\begin{abstract}
Resumen: Las condiciones para el estudio del Estado están atravesando una reconfiguración marcada por una serie de nuevas formas y procesos. Por eso es necesario revisar las nociones convencionales del concepto mismo de Estado y construir la base para una concepción más adecuada a la realidad de la política y el gobierno hoy. El trabajo presenta dos corrientes que aportan al estudio del Estado en el sentido mencionado: la antropología del estado y los estudios de gubernamentalidad. El objetivo del trabajo consiste en señalar cómo ellas construyen un marco de análisis que supera algunas de las debilidades de otros enfoques.
\end{abstract}

Palabras-clave: Estado, política, gubernamentalidad, antropología del estado.

\section{Beyond the State. Perspectives and lineaments or its study and definition}

Abstract: The conditions for the study of the state are undergoing a reconfiguration marked by a series of new forms and processes. That is why it is necessary to check conventional notions of the very concept of state and to provide the basis for a more adequate conception to the political and governmental reality today. The present work introduces two approaches that contribute to the study of the state in the aforementioned direction: state anthropology and governmentality studies. This work aims at pointing out how they both build an analytical framework that surpasses the weaknesses of other approaches.

Key-words: State, politic, state anthropology, governmentality

\footnotetext{
* Posdoctorado de Investigación. Instituto de Investigaciones Sociales. UNAM. Universidad Nacional Autónoma de México. 2008-2010, México. E-Mail: pcmussetta@gmail.com
}

Latitude, Vol.2, nº 1, pp. 06-25, 2008. 


\section{Diagnóstico}

Hace unas tres o cuatro décadas atrás definir al Estado resultaba una tarea más o menos sencilla en tanto más allá de las diferentes tendencias, existía un consenso relativo acerca de su definición y características elementales. Hoy difícilmente podamos seguir afirmando lo mismo. Actualmente en el ámbito del estudio del Estado algunos factores desempeñan un rol fundamental y determinan ampliamente una nueva configuración de este campo de análisis. La globalización por un lado, pone de manifiesto la limitación de algunas capacidades del Estado ante las entidades supranacionales y pareciera volverlo -al Estado- cada vez más irrelevante -no sólo como actor económico sino también como un contenedor cultural y social-. (TROUILLOT, 2001, p.125) Por otro lado, asistimos también a importantes cambios en las formas de intervención estatal, como por ejemplo la cada vez mayor presencia de nuevos estilos de gobierno, distintos del modelo del control jerárquico y caracterizados por un mayor grado de cooperación e interacción entre el Estado y los actores no estatales. Los límites y capacidades estatales se modifican y ya no es siempre posible definir claramente dónde termina lo público y comienza lo privado.

No podemos negar que el Estado ha cambiado. Escalante nombra a este fenómeno como la expansión de los márgenes del Estado e inteligentemente enumera una lista de hechos que comprueban la situación: "la expansión de la economía informal, la venta ambulante y la organización de sistemas de producción, comercialización e incluso sistemas financieros informales, el surgimiento de una gran industria de la falsificación y la piratería, la copia de libros, música, películas o ropa, la ocupación ilegal de tierras y la de viviendas, la organización de redes de migración ilegal hacia Europa y Estados Unidos, el extenso campo de la delincuencia organizada, en un espectro que va del narcotráfico al secuestro." (ESCALANTE, 2007, p. 66) Para muchos este panorama desdibuja la relevancia del Estado. Para otros este mismo escenario se constituye en el lugar desde donde argumentar que más allá de los procesos de transnacionalización y de modificación de las formas tradicionales de gobierno y de los contornos del Estado éste en lugar de marchitarse o esfumarse, subsiste. Los motivos con los que se argumenta su permanencia son de diversa índole ya sea porque es un ámbito clave a través del cual la globalización opera; (SHARMA y GUPTA, 2006) o porque a pesar de que el poder post moderno es difuso, es el Estado el lugar a través del cual el poder fluye y se hace objeto de lucha, aun en las sociedades postnacionales. (MIGDAL, 2001), o bien porque no hay una alternativa como forma política de organización social (ESCALANTE, 2007 p. 77)- pero todos tienen en común un absoluto convencimiento de que el Estado no está en camino hacia su desaparición. En la base de estas expresiones se encuentra la idea -la cual compartimos- que en realidad ninguno de estos procesos que marcan una transformación del campo político del Estado lleva a una situación en la que deba abandonarse el concepto de Estado o que el Estado esté en decadencia como objeto de estudio.

Latitude, Vol.2, nº 1, pp. 06-25, 2008. 
En síntesis, las condiciones para el estudio del Estado han cambiado -porque el mismo Estado ha cambiado- y por lo tanto irrumpen o modifican algunas de las nociones convencionales del concepto mismo de Estado. Es evidente que las imágenes y el vocabulario de la política y el poder han sido vulnerados por la política contemporánea misma; de manera que algunas formas que fueron exitosas en otras épocas ya no pueden ser calibradas en términos del acontecer político actual. (ROSE, 2004 p. 2) La revisión de las maneras que analíticamente nos permitan acceder a estas particulares configuraciones que adquiere el Estado ya no puede postergarse. La demanda se orienta hacia una base para definir una concepción más adecuada a la realidad de la política y el gobierno hoy. Estas bases no son nuevas pero sí impostergables y comienzan por entender al Estado como algo más que el conjunto de instituciones del aparato gubernamental y amplían su definición a otros ámbitos no siempre relacionados a la acción de gobierno. De la misma manera, suponen que el Estado no es el actor racional que opera -separada y jerárquicamente- sobre la sociedad. El Estado es elemento de la configuración del campo sociopolítico, que entre otras cosas se define por ser cambiante, inestable, ambiguo y no homogéneo.

Este artículo presenta dos corrientes que comparten estas preocupaciones y pretenden aportar al estudio del Estado en el sentido mencionado. El objetivo del trabajo consiste en señalar cómo ellas construyen un marco de análisis que supera algunas de las debilidades de otros enfoques y que por lo tanto son marcos más apropiados para el estudio del Estado en sus modalidades actuales. Especialmente deseamos reseñar una mirada particular, un punto de vista y posicionamiento frente al Estado que además de contribuir con elementos de análisis, básicamente modifique las maneras de preguntarnos por el Estado y por su entorno.

Durante el desarrollo de este trabajo varios planos o niveles diferentes quedan implicados. Por un lado, un nivel empírico o práctico que se refiere a las modalidades actuales que adquiere el Estado. Estos cambios en el nivel empírico y práctico, llevan a plantearnos cuestiones en un plano analítico que oriente acerca de cómo abordar esas particularidades del Estado actual. Segundo, pero probablemente lo más importante, hay otra discusión implícita, de fondo y funda mental, que refiere a un nivel teórico $o$ conceptual acerca de lo que es, o sobre cómo definirlo y entenderlo. El desarrollo detallado de este último plano, probablemente esté fuera del alcance de este artículo, pero es una discusión que constantemente estará, aunque de manera implícita, presente. No obstante queremos remarcar que la importancia de lo que aquí manifestamos no es un asunto relativo única y exclusivamente a la definición del Estado. Sería muy simple si sólo fuera una disputa por conceptos. Más bien el punto más importante aquí son los problemas reales, concretos y verdaderos del presente político, los cuales creemos son, hasta cierto punto, indefinibles con los recursos analíticos convencionales.

Latitude, Vol.2, nº1, pp. 06-25, 2008. 
El artículo se organiza de la siguiente manera. En la primera parte presentamos una definición de Estado que creemos forma parte del tipo de enfoques que opacan los problemas que mencionamos. El objetivo es ilustrar algunos aspectos problemáticos para un apropiado entendimiento del Estado. En la segunda parte exponemos los argumentos que fundamentan una mirada diferente a la de la sección primera y que creemos más adecuada para el estudio del ámbito estatal. La tercera sección presenta dos marcos conceptuales concretos que han desarrollado -desde posiciones diferentesesta perspectiva de estudio y entendimiento del Estado y proponen modos de análisis específicos para los problemas de gobierno actuales: la gubernamentalidad y la antropología del Estado. En los últimos párrafos, dejamos planteados algunos interrogantes que la discusión anterior abre.

\section{El Estado como el actor central del ámbito político}

El análisis político del siglo veinte está contundentemente asociado al Estado y su preponderancia en la explicación del orden sociopolítico. El libro Bringing the state back in ${ }^{1}$ es una incuestionable referencia al momento de señalar algunas de las tendencias o propuestas Estado-céntricas más actuales ${ }^{2}$. Para muchos -esta obra compilada por Evans, Rueschemeyer y Skocpol- es una apología del Estado como un actor de peso que afecta los procesos políticos y sociales a través de sus políticas y sus modelos de relaciones con los grupos sociales. (ROSE, 2004; MIGDAL, 2001; STEINMETZ, 1999) ${ }^{3}$. Pero la mayor o menor centralidad del Estado no es la cuestión que más peso tiene en nuestro argumento. Lo que realmente nos importa de estos planteos que destacan la centralidad del Estado es una de sus consecuencias: la

${ }^{1}$ Bringing the state back in. Peter Evans, Dietrich Rueschemeyer \& Theda Skcpol. Cambridge University Press. 1994.

${ }^{2}$ La tradición que pretendemos señalar es mucho más amplia y más antigua que la señalada en Bringing the state back in y no podemos reseñarla de manera extensa en este documento. Pero la seleccionamos de entre muchas por dos razones: en primer lugar porque es una de las fuente más señaladas para referirse al problema que aquí estamos tratando de exponer. Ver Rose, 2004, Migdal, 2001, Steinmetz, 1999. Y segundo porque allí queda muy claro no sólo que el Estado "importa" en la explicación del orden y su constitución, sino que además, éste no ha sido suficientemente tenido en cuenta por lo que es necesario traerlo nuevamente a la escena del análisis. Bringing the state back in es un manifiesto que reivindica la centralidad del Estado en la explicación de los procesos sociales, políticos y económicos.

${ }^{3}$ Más allá de la preponderancia conceptual del Estado hubo algunos otros esfuerzos por cambiar el foco de análisis, descentrándolo del Estado. Mitchell explica que tomando conceptos y métodos de investigación de campos como la antropología, la ciencia política planeó cambiar su preocupación del Estado a la sociedad abriendo el trabajo del proceso político a una inspección más cercana. Ver: Timothy Mitchell (2006).

Latitude, Vol.2, nº 1, pp. 06-25, 2008. 
definición misma del Estado en ellos presente. Se trata de un objeto cuya definición se juega en algunos atributos entre los cuales se destacan la autonomía y jerarquía (1), su institucionalidad y estructura (2), su delimitación y nitidez (3), y en gran medida, su existencia previamente dada a muchos de los procesos que lo rodean (4). En los párrafos que siguen describimos estos atributos, para dar forma a la noción de Estado presente en los enfoques dominantes, y que aquí creemos imprescindible dejar atrás.

(1) El Estado moderno ha sido analizado en términos de una tendencia aparentemente ineludible a centralizar, controlar, regular y administrar. La teoría política y social puso mucha atención en este rol expansivo del Estado y, como sostiene Rose, "encontraron la mano del Estado aún cuando ésta parecía estar ausente y criticaron las concepciones prevalecientes del pluralismo político porque parecían ignorar el rol estructurante del Estado". (2004 p. 15) Desde esta perspectiva el Estado es entendido como un actor que tiene la capacidad para diseñar las estructuras políticas y sociales; posición que implica un papel mucho más central del Estado en relación a sus "otros" tradicionales: la economía, la sociedad, la cultura. El Estado aparece como una entidad especial y separada, que es realmente poderosa y que además un aspecto de su poder reside en su habilidad para prevenir un estudio adecuado de él mismo. El análisis político nos ha presentado durante mucho tiempo al Estado como si fuera una entidad autónoma cuyas acciones no son determinadas por las fuerzas de la sociedad. De esta manera vendría a ser una estructura que está sobre y por encima de los individuos que integran la sociedad, y que tiene como uno de sus atributos la soberanía.

(2) Si el Estado es entendido como un conjunto de instituciones y estructuras, lo que importa es su configuración organizativa, el conjunto de sus agencias y funciones. Rose y Miller han definido este rasgo de la sociología del Estado como "realismo". Sostienen que la sociología del Estado es y ha sido realista porque enfatiza los aspectos formales de las instituciones y los procesos y busca caracterizar las configuraciones reales de personas, organizaciones y eventos en períodos particulares; y que identifica los determinantes de la fuerza que tienen explicando sus transformaciones. (STEINMETZ, 1992, p. 177) se preocupa también por este mismo rasgo pero lo elabora en términos de una falta de atención hacia los aspectos culturales, e indica que este enfoque del Estado elucida las condiciones estructurales bajo las cuales los funcionarios y los statemakers se liberan de las demandas de los actores de la clase dominante. Pero no ofrece un análisis del contenido real de las políticas que esos actores buscan implementar (STEINMETZ, 1999a p. 18) ${ }^{4}$. En esta misma línea, para Migdal el problema es que estos estudios se centran en la estructura del Estado y sólo después, se ocupan de ver cómo ésa estructura encaja en un mundo de otras

4 Y si se ocupan de corregir el tema, ocasionalmente señalan el impacto de las ideas o los intelectuales en la política estatal. Pero cualquier atención al proceso de toma de decisión abre la caja de pandora de la subjetividad y la cultura (Steinmetz, 1999, p.18).

Latitude, Vol.2, nº1, pp. 06-25, 2008. 
estructuras. (STEINMETZ 2001b p. 236) Estas formas de construir la mirada sobre el Estado, han ido mistificando al Estado así como sus capacidades. Paradójicamente, la consecuencia de esta mirada abarcadora sobre el Estado, es una mirada limitada.

(3) Otro rasgo de la definición del Estado es que establece límites claros y definidos en la relación Estado-sociedad. El lenguaje político tradicionalmente ha sido estructurado por la oposición entre Estado y sociedad civil, público y privado, gobierno y mercado, coerción y consenso, soberanía y autonomía. En la clara dualidad Estado-sociedad civil el Estado es una realidad construida, que cataliza los procesos políticos, mientras que la sociedad civil es el dominio de las relaciones sociales espontáneas orientadas por intereses privados (SANTOS, 1998 p. 140). Pero estas dicotomías no caracterizan adecuadamente las diversas maneras en que se ejerce el gobierno en las democracias liberales avanzadas (ROSE y MILLER, 1992, p. 174). Por otra parte el límite que entre ellas se establece es una objetivación que constituye en realidad una demarcación móvil, sujeta a una construcción y deconstrucción continua (STEINMENTZ, 1999, p. 25).

(4) Por último, queremos señalar que el Estado es ampliamente reconocido como una organización dada, coherente, homogénea, sin contradicciones; y definido previamente. Entender al Estado como dado genera una idea de coherencia, de afinación y coordinación a partir de la existencia de un nudo de coincidencias ideológicas básicas. Pero la realidad ha demostrado por el contrario que en general los discursos conviven con prácticas incompatibles. El Estado ya no puede ser considerado como actor, con la coherencia, agencia, autonomía que este término presume. Los múltiples acuerdos que producen la separación aparente del Estado crea un efecto de agencia, una autonomía parcial con consecuencias concretas. Pero esta agencia siempre será contingente a la producción de diferencias, aquellas prácticas que crean el límite aparente entre el Estado y la sociedad (MITCHELL, 2006, p. 176).

\section{Del Estado como centro al más allá del Estado}

Los autores que retomamos para darle forma a la perspectiva que queremos presentar para entender el Estado insisten, demostrando la dificultad de la delimitación institucional y procedimental del Estado, que en lugar de verlo como una institución real autocontenida, es impostergable enfocar el análisis más allá del Estado: en la naturaleza, tácticas, y efectos de poder que operan a través de la formación social entera. Como lo expresa Trouillot (2001, p. 126), es necesario teorizar el Estado más allá de sus obviedades empíricas y centrarse en los múltiples lugares en los cuales los procesos y prácticas son reconocibles a través de sus efectos. El poder del Estado no tiene una única fijación institucional de manera que sus efectos nunca se obtienen solamente a través de las instituciones o sitios gubernamentales.

Latitude, Vol.2, nº 1, pp. 06-25, 2008. 
La alternativa al enfoque Estado-céntrico en cambio, toma muy en serio el carácter elusivo del límite entre el Estado y la sociedad, y lo plantea no como un problema de precisión conceptual sino como una pista sobre la naturaleza misma del fenómeno. Antes que buscar una definición que encaje perfectamente en el límite Estado- sociedad (para demostrar cómo el objeto de un lado influye o es autónomo de la idea que existe del otro lado) necesitamos examinar el proceso político a través del cuales no muy definidas y poderosas distinciones entre Estado y sociedad se producen (SHARMA y GUPTA, 2006 p. 170). Las investigaciones sobre el Estado, especialmente los que lo toman como una amplia estructura que determina, han fallado en responder a preguntas cotidianas, a la idea de cómo las prácticas de los burócratas nos hablan de los efectos del Estado en las prácticas cotidianas de las personas. Pero especialmente esa perspectiva oscurece las características de las formas modernas de poder político. Por todo esto, creemos necesario problematizar las distinciones entre Estado y sociedad civil. De tal manera que el enfoque que aquí reconstruimos, rechaza al Estado "centrado", como el centro de poder por ser una concepción poco apropiada para la realidad de la política y el gobierno.

La insistencia en una propuesta que se deshaga de los dualismos (Estado/sociedad, mercado/familia) se funda en el hecho que las imágenes y el vocabulario de la política y el poder han sido desafiados por la política contemporánea misma. La dicotomía del pensamiento político tradicional no puede aprehender estas complejas maneras. El estudio del Estado actual debe ser despojado de los mitos sobre su unidad y omnipotencia. Como dice Migdal (2001, p. 23) parafraseando a Elias, no se trata de ver el Estado como "es", sino de ver "en qué se convierte o se ha convertido en el pasado, o se está convirtiendo en el presente, y podría convertirse en el futuro. La propuesta que estamos reconstruyendo está formada por algunas dimensiones que implican una reconceptualización del Estado y que cuestionan las características que mencionábamos antes acerca de la usual definición del Estado. Los postulados más importantes de la definición que tratamos de armar, se basan en la necesidad de ver al Estado más allá de sus instituciones o lugares comunes, y entenderlo en cambio como un proceso, que no se forma de una sola vez, y que no es completamente autónomo de los demás campos o procesos que lo circundan. En esta sección presentamos los puntos que dan forma lo que creemos un enfoque adecuado para el estudio y entendimiento del Estado actual.

\section{El proceso de formación del Estado}

El Estado no es una estructura fija y dada, sino que es un proceso; un proceso que inicia en la red de relaciones entre el Estado y la sociedad, y se define en la naturaleza particular de las mismas, así como en sus encuentros con otras fuerzas sociales. Si el Estado no es una entidad completamente autónoma, como creemos, se vuelve

Latitude, Vol.2, nº1, pp. 06-25, 2008. 
importante entender cómo se orienta hacia esos compromisos con esas otras fuerzas sociales.

Esta manera dinámica de pensar al Estado en tanto proceso, ha sido desarrollada por varios autores, en conjunto con la idea de formación de Estado. Este concepto identifica el proceso de formación de Estado con aquellas situaciones en las que se diseñan o transforman situaciones durables o rasgos estructurales de los Estados. Los rasgos estructurales se supone que incluyen modelos de prácticas así como las comprensiones intersubjetivas en las cuales esas prácticas están arraigadas (STEINMENZ, 1999, p. 9). La formación del Estado ha sido entendida en el ámbito de la teoría política como un momento inicial -cuasi mítico- en el cual se crean organizaciones hegemónicas, centralizadas y de ejercicio de coerción dentro de un territorio dado, esto es, particularmente se lo asocia con el momento de la creación de Estados nación. A partir de este punto todas las actividades que le siguen a este momento fundante se describen y estudian como policymaking y no como formación de Estado. Sin embargo, no es apropiado sostener que los Estados son formados en un evento de una vez y para siempre; sino que constantemente se (trans)forman en un proceso de cambios estructurales; que no son autónomos de fuerzas culturales y que tienen un contexto histórico y social que los define en gran medida. Las políticas, las leyes y el derecho en general son aspectos de la formación del Estado porque afectan la estructura misma de ese proceso; así como también la naturaleza y tipo de límites entre el Estado y la sociedad. La sociología de la formación de Estado ha mostrado que éste se hace en prácticas que tienen que ver poco con el Estado entendido en los términos clásicos. Más bien, el Estado moderno gobierna sobre la base de una elaborada red de relaciones formadas entre el complejo de instituciones, organizaciones, y aparatos que lo conforman y entre las instituciones estatales y no estatales. Por eso nuestro enfoque no estudia el Estado hecho, ni postula una mirada que indague los lugares conocidos de los gobiernos; sino que se ocupa de los procesos estatales y sus efectos en sitios menos obvios que aquellos de La política institucionalizada y las burocracias institucionalizadas, por eso necesita un método que mire en todos los niveles del Estado, trascendiendo su institucionalidad.

La idea de Estado como proceso nos recuerda que el Estado moderno tiene una naturaleza arbitraria, construida, fragmentada, cambiada. $Y$ en este sentido es legítimo el llamado que se hace para girar la atención analítica y centrarla en el estudio de Estados complejos y heterogéneos, de la diferencia, el conflicto, la contradicción (GOLDSTEIN, 2004 p. 588). Los Estados no siempre tienen metas claras y los intereses no son siempre del todo discernibles. La formulación de la política estatal es mucho más un producto de la dinámica que se consigue con la resistencia a la dominación o con la imposición de límites de algunos sectores que un resultado de una idea pensada en el seno del Estado y formulada a través de un proceso legislativo (MIGDAL, $2001 \mathrm{p}$. 112).

Latitude, Vol.2, nº1, pp. 06-25, 2008. 


\section{El carácter no fijo del límite}

No aceptar al Estado como dado, es no considerarlo como una entidad distinta, fija, unitaria, que desciende al terreno en el cual otras instituciones existen y funcionan. El análisis de la formación del Estado no asume que el Estado existe simplemente en la cúspide de la sociedad y que es el lugar central de poder. Por el contrario, el problema es resolver cómo el Estado viene a asumir ese lugar vertical. Examinar la formación del Estado es entender cómo el Estado y sus límites están culturalmente construídos.

El vínculo entre el Estado y la sociedad tampoco está dado a priori sino que es un efecto de poder. Por eso podemos conceptualizar al Estado más bien dentro -y no automáticamente distinto de- otras formas institucionales a través de las cuales lo social es vivido. En esta perspectiva el vínculo entre el Estado y su otro está problematizado. Ya sea la sociedad civil, la economía, comunidad. Y esta definición lleva a que también se problematice la relación y el vínculo entre el ámbito público y privado. Mitchell (2006) demuestra la naturaleza efímera de este vínculo y sostiene en cambio que en lugar de separar estas dos entidades, esta línea está marcada internamente y sirve para mantener el orden social. Antes que separación nítida, existe imbricación entre lo social y el Estado, y la naturaleza de este vínculo entre el Estado y el no Estado es socialmente construida. Al mismo tiempo esto demuestra los preceptos abrumadores de poder que tienen estas construcciones.

Dentro de esta visión, el Estado aparece como un campo abierto con múltiples límites pero sin estar fijado institucionalmente, lo cual significa que debe ser conceptualizado en más de un nivel (TROUILLOT, 2001). Por eso, aunque está ligado a una serie de aparatos que pueden ser gubernamentales, no es un aparato sino un conjunto de procesos. No está atado necesariamente a una institución ni una institución sola puede abarcarlo por completo.

\section{Hacia una reconceptualización del Estado}

Geertz nos dice que hay que dejar de ver al Estado como la máquina del Leviatán, como una esfera que comanda y decide. Más bien hay que mirar alrededor del Estado, en el tipo de sociedades en que se inscribe. Menos Hobbes y más Maquiavelo, menos la imposición del monopolio de la soberanía y más el cultivo de oportunidades. Menos el ejercicio de la voluntad abstracta, y más la adaptación al contexto y el logro de ventajas visibles (GEERTZ, 2004, p. 580). Se ilumina así, la

mutua transformación del Estado y de los otros grupos sociales, así como las

Latitude, Vol.2, nº 1, pp. 06-25, 2008. 
limitaciones mismas con las que se encuentra el Estado. Ésta es sólo una modalidad de gobierno, pero no la única ni más importante fuente de poder. Como sostiene Rose, ¿quién necesita hoy un Estado grande, centralizado para reproducir las relaciones desiguales de poder cuando el mismo resultado puede ser alcanzado por mecanismos de poder y sistemas de gobierno que producen el autogobierno, el auto reforzamiento, el auto compromiso, de los individuos y las comunidades? (ROSE, 2004). Muchas prácticas y procesos que parecen gubernamentales obtienen espacios en ámbitos no gubernamentales. A su vez estas prácticas producen efectos de Estado tan poderosos como los gobiernos nacionales. Hacia aquí apunta la reconsideración del concepto de Estado que estamos planteando. La reconceptualización del Estado por la que abogamos consiste en deshacernos de aquellas nociones que planteamos al inicio para generar una diferente, que cambiando la manera de entender al Estado, enfatice aspectos y dimensiones desestimados en las tendencias predominantes. Creemos que lo más importante de este redireccionamiento de la mirada, es la manera de concebir la naturaleza del Estado, de definirlo.

\section{Los desarrollos del enfoque}

Las potencialidades de esta manera de entender el Estado y sus formas, pueden apreciarse en algunos desarrollos conceptuales particulares. Aquí queremos exponer los argumentos elementales de dos planteamientos. Ambos coinciden en la necesidad de descentralizar el estudio del Estado en algo más que sus instituciones, y además su importancia radica en que despliegan una serie de herramientas de análisis para abordar las problemáticas del Estado en funcionamiento. Una de ellas es la idea de gubernamentalidad, planteada por Foucault y luego apropiada por un grupo de autores anglosajones. La segunda contribución a la que nos referiremos se sintetiza en un enfoque disciplinar denominado antropología del Estado.

\section{La gubernamentalidad}

Una de las contribuciones más importantes en esta línea de análisis e interpretación del Estado corresponde al concepto de gubernamentalidad desarrollado originalmente por Foucault. En estas definiciones de rasgos durables del Estado, es decir, en el proceso de formación de Estado, es posible identificar una manera particular de responder la pregunta sobre qué debe ser gobernado, por quién y a través de qué procedimientos. La gubernamentalidad se refiere a una manera de dar respuesta a estas preguntas.

Latitude, Vol.2, nº1, pp. 06-25, 2008. 
La gubernamentalidad es parte de un intento por realizar un movimiento teórico que permita ir más allá del marco del Estado dentro del cual el estudio de la problemática del gobierno y el poder había sido confinado. Esto es precisamente lo que intenta decir la noción de gubernamentalidad de Foucault. Sin este concepto no es posible entender la idea foucaultiana de Estado. La gubernamentalidad es el marco más amplio en el cual el autor sitúa el estudio del Estado.

La relación entre Estado y gubernamentalidad es estrecha. Esta última trasciende al Estado pero no puede ser pensada sin él. La relación entre Estado y gubernamentalidad es una relación compleja que no puede ser pensada como una relación de superación de conceptos o reemplazo de unos conceptos por otros. La gubernamentalidad es interna y externa al Estado dado que son las tácticas de gobierno las que hacen posible la definición continua de lo que está dentro de la competencia del Estado y lo que no, lo público y lo privado, y demás. De esta manera el Estado sólo puede ser entendido en su supervivencia y en sus límites sobre la base de las tácticas generales de la gubernamentalidad.

La gubernamentalidad inaugura no sólo una manera diferente de pensar al Estado y su entorno sino que al mismo tiempo sienta las bases para una perspectiva de estudio del Estado, un enfoque, un marco conceptual. Asimismo la gubernamentalidad es un concepto que trae consigo una serie de implicaciones analíticas que se corresponden o no son independientes de la manera en que Foucault se posiciona ante la realidad social.

En primer lugar, es un concepto que pone de manifiesto el carácter contingente de los procesos sociopolíticos. La gubernamentalidad se caracteriza por un interés en el análisis genealógico, es decir, enfatiza las maneras en las que el presente es el resultado bastante arbitrario de contingencias pasadas. Como explica O’Malley, Foucault otorga especial importancia a la contingencia del desarrollo histórico y aquí yace una sospecha sobre cómo complejas transformaciones en el gobierno se reducen a efectos pre ordenados de ciertas lógicas meta históricas - que las grandes teorías vendrían a revelar- (O’MALLEY, 2006, p. 23). En lugar de las sociologías causales y deterministas este análisis en cambio busca promover la idea de que las cosas no necesariamente deben ser como son en el presente y que el futuro - más que ser el resultado de alguna lógica de desarrollo - está abierto (O’MALLEY, 2006, p. 26). En la analítica de la gubernamentalidad el énfasis tiene que ser puesto en cómo aquello que aparece como necesario debe ser entendido como un resultado de una reunión de materiales, ideas, prácticas y otros elementos en respuesta a una comprensión específica de la naturaleza de los problemas a resolver. No hay que dar por supuesto lo que aparece como natural. Más bien hay que considerarlo como inventado, una construcción intelectual que refleja o corporiza interpretaciones gubernamentales de las maneras en que las cosas son.

Latitude, Vol.2, nº 1, pp. 06-25, 2008. 
En segundo lugar, el enfoque de la gubernamentalidad no busca la verdad de la política, sino que se pregunta por sus implicaciones para la vida de las personas. Estas implicaciones no están reveladas en alguna teoría sino que aparecen en la superficie del discurso político mismo y en las técnicas que utiliza para producir sus efectos intencionales. En vez de imponer una verdad, esta perspectiva se dirige al régimen de verdad adoptado por los programas de gobiernos que se están analizando, y eso se vincula al carácter contingente de los eventos: las cosas podrían haber sido imaginadas de otra manera y estos otros posibles imaginarios podrían haber sido utilizados para crear otro mundo social y político (O’MALLEY, 2006, p. 28).

En lugar de asumir que el Estado es el ente supremo de poder exclusivamente para dominar y gobernar, la gubernamentalidad ofrece una manera de entender cómo el poder es ejercitado en la sociedad a través de relaciones sociales variadas, instituciones, y cuerpos que no encajan automáticamente bajo el rubro del Estado. El Estado, en este marco, es un nodo de redes horizontales de instituciones e individuos a través del cual el poder es ejercitado, y no es la institución más vertical de emanación de poder.

La re-caracterización de la cuestión del poder político en términos de la problemática de la gubernamentalidad, va acompañada de una serie de herramientas conceptuales a través de las cuales es posible el análisis de las formas de gobierno. Rose y Miller -dos de los autores que retoman la noción de la gubernamentalidad en el estudio de las problemáticas de gobierno-proponen un tríptico conceptual: racionalidades políticas, programas de gobierno y tecnologías de gobierno.

Las concepciones más o menos coherentes de fines de gobierno, que constituyen un campo de intervención legítima y se expresan en un lenguaje particular son racionalidades políticas. El proceso de formación de Estado contiene una o varias racionalidades políticas. Al mismo tiempo y junto con las racionalidades políticas, estos modos de gobierno implican el desarrollo de ciertas y determinadas tecnologías de gobierno que serían las prácticas y técnicas para la transformación de actividades, condiciones y sujetos en un campo de intervención (CURTIS, 1995, p. 575).

Estos dos conceptos (racionalidades políticas y tecnologías de gobierno) corresponden a la tradición de la idea de gubernamentalidad -desarrollada originalmente por Foucault-. Y aunque es una línea teórica muy específica, no deja de ser una pieza que complementa el planteo que venimos desarrollando, ya que en lugar de asumir que el Estado es el ente supremo de poder, resalta la necesidad de entender cómo el poder es ejercitado en la sociedad a través de variadas relaciones sociales, instituciones y cuerpos que no necesariamente encajan automáticamente bajo el rubro del Estado ${ }^{5}$.

${ }^{5}$ La gubernamentalidad, para Foucault es el conjunto constituido por las instituciones, los procedimientos, análisis y reflexiones, los cálculos y las tácticas que permiten ejercer esa forma

Latitude, Vol.2, nº1, pp. 06-25, 2008. 
La ampliación de la discusión del Estado hacia otros ámbitos es el quid de los estudios que ya no se interesan -al igual que Foucault- por el Estado en sí, sino por la gubernamentalidad, en un sentido amplio del Estado funcionando. Luego de (y e $\mathrm{n}$ algunos casos junto con) Foucault un grupo de autores denominados anglofoucaultianos quienes desarrollaron los governmentality studies ${ }^{6}$. La proliferación de los governmentality studies ha sido en estudios sobre el neo-liberalismo -como racionalidad política predominante en las sociedades "liberales avanzadas" (Rose, 1999)-, así como en el análisis sobre las estrategias de "gobierno a la distancia" que se desprenden del concepto de biopolítica también planteado por Foucault.

\section{La antropología del Estado}

La antropología del Estado es un enfoque disciplinar que engloba los conceptos y definiciones que presentamos a continuación; y se define no tanto por el método etnográfico que deja disponible para el abordaje del Estado, sino por estudiar los componentes desagregados del mismo, en su contexto así como las relaciones entre él $\mathrm{y}$ otros actores que se mueven en ese mismo medio. Esta perspectiva impone una serie de movimientos analíticos que contribuyen a dar forma a una nueva manera de conceptualizar al Estado.

Por un lado, esta perspectiva entiende que el Estado está formado por aspectos simbólicos así como materiales, y que ambos son elementales para entender cómo el Estado es, cómo se diferencia de otras formas institucionales y cuáles efectos tiene esta constitución sobre la operación y difusión del poder en la sociedad (Sharma y Gupta, 2006 p. 8). De esta manera, el enfoque antropológico del Estado sostiene que las respuestas al estudio del Estado no pueden ser encontradas tratando separar las formas materiales del Estado de las formas ideológicas. Los aspectos materiales y simbólicos del Estado son mejor entendidos como dos aspectos de un mismo proceso. El fenómeno que llamamos Estado, emerge de técnicas que permiten a las prácticas

bien específica, aunque muy compleja de poder que tiene por blanco principal la población, por forma mayor de saber la economía política y por instrumento técnico esencial los dispositivos de seguridad (Foucault, 2006, p. 136).

${ }^{6}$ El término anglofoucaultianos (De Marinis, 1999), remite a un conjunto de estudios que se autonuclearon hacia fines de los años ochenta en torno de la red "Historia del presente" (Rose, O'Malley, Valverde, 2006), que comprende un importante cuerpo de trabajos con epicentro en Londres. Muchas veces esta Red describe una realidad doble: por un lado, si bien se trata de un grupo que ha producido una vasta cantidad de trabajos, aún han sido escasamente traducidos al español; por el otro, los estudios acerca de la gubernamentalidad tienen también un escaso desarrollo fuera del mundo anglosajón. (Grinberg, 2007). Como sostiene Grinberg (2007), aun así es posible encontrar un conjunto de autores que están trabajando desde esta perspectiva; y una importante contribución a la difusión en español de este importante conjunto de ensayos, libros y artículos producidos por esa Red es la del .

Latitude, Vol.2, nº1, pp. 06-25, 2008. 
materiales cotidianas tomar la apariencia de una forma abstracta y no material. Cualquier intento de separar lo abstracto o ideal de su realidad material, o dar por hecha esta distinción, fallará al tratar de entender el Estado. La tarea de una teoría del Estado no es clarificar la distinción sino historizarla. De esta manera, la materialidad del Estado reside mucho menos en las instituciones que en el repaso de procesos y relaciones de poder (Trouillot, 2001).

Si el Estado es un conjunto de prácticas y procesos y sus efectos, estas prácticas, procesos y efectos no necesariamente aparecerán alrededor de importantes ámbitos gubernamentales. El desafío es estudiar estas prácticas, funciones y efectos sin prejuicio de los ámbitos o formas de los encuentros.

Por otra parte, el Estado tienen una naturaleza ambigua y no siempre sus expresiones son coherentes. Por eso este enfoque plantea la necesidad de realizar una mirada desagregada del Estado, de sus componentes, que muestre la naturaleza múltiple, pluricéntrica y fluida del Estado. En lugar de descartarlas, la antropología del Estado pretende darle sentido a estas tensiones y estudiarlas como importantes. Al mismo tiempo, estas tensiones se hallarán no sólo en la política organizada sino en las numerosas prácticas a través de las cuales los ciudadanos se encuentran con el gobierno y con instituciones semejantes al Estado y los procesos que los interpelan como individuos. La antropología no estudia al Estado hecho, ni espera que la mirada etnográfica indague los lugares conocidos de los gobiernos. Es necesario estudiar las instituciones y las prácticas. Sin embargo tenemos que estudiar también los procesos estatales y sus efectos en sitios menos obvios que aquellos de la política institucionalizada y las burocracias institucionalizadas. Hay que insistir en los encuentros que no son inmediatamente transparentes.

El enfoque se interesa por los aspectos dinámicos de los Estados y analiza cómo sus varios componentes se relacionan unos a otros. Por eso la antropología como enfoque de estudio del Estado rechaza los presupuestos implícitos en muchos estudios concernientes a un llano y claro entrelazamiento dentro y entre los órganos de organización del Estado o de un Estado que simplemente refleja la voluntad de sus líderes.

En definitiva pensar el Estado como proceso, como lo hacen estos autores, implica un movimiento desde un análisis estructural y funcional del Estado (que lo ve como un actor autónomo o un conjunto de instituciones convencionales de gobierno que sirve a los intereses de clases y grupos particulares) hacia uno que lo entienda como un efecto de prácticas cotidianas, de discursos representacionales, y de múltiples modalidades de poder. Estos autores demuestran la dificultad en la delimitación institucional y procedimental del Estado. Antes que verlo como una institución concreta, enfocan el análisis en la naturaleza, tácticas, y efectos del poder que operan a través de la formación social entera.

Latitude, Vol.2, nº1, pp. 06-25, 2008. 
Estudiar al Estado descentrado, en sus componentes nos lleva a un cambio en la definición misma del Estado. Nuevos procesos y nuevas prácticas que parecen negar o traspasar las formas estatales, se introducen en los intersticios abiertos. Muchas prácticas y procesos que parecen gubernamentales obtienen espacios en ámbitos no gubernamentales. A su vez estas prácticas producen efectos de Estado tan poderosos como los gobiernos nacionales. Por eso es necesario teorizar el Estado más allá de sus obviedades empíricas. Hay que centrarse en los múltiples lugares en los cuales los procesos y prácticas son reconocibles a través de sus efectos (TRUILLOT, 2001, p. 126).

Este giro que impone la antropología del Estado resalta un énfasis en lo cotidiano, como espacio de producción, negociación, transacción y contestación de significados dentro de redes y relaciones de poder mayores.

La diferencia de esta nueva manera de entender al Estado, es definida por Trouillot como un cambio en la relación entre el objeto de estudio y el objeto de observación: no son lo mismo. El Estado nunca fue un objeto de observación. Siempre fue una construcción (en el mejor de los casos teórica) esto es, un objeto de estudio. Por eso la tarea teórica es ubicar las conceptualizaciones del Estado sobre las cuales podemos construir este objeto de estudio de manera de dar cuenta de la historia reciente y del rol ideológico del Estado. Hay que problematizar la relación entre objeto de estudio y de observación (TROUILLOT, 2001). Por eso la tarea y el reto es además metodológico: si el Estado no está dado allí afuera, cuál es el objeto de observación? Si el Estado no es algo dado ni únicamente lo vemos en sus organizaciones, entonces, ¿dónde se produce el encuentro analítico con el Estado?

\section{Las prácticas de Estado}

Para la antropología del Estado no es posible entender el Estado si no es a través de las prácticas estatales. Éstas constituyen una puerta de acceso al modo en que los Estados son producidos y reproducidos. La herramienta de prácticas de Estado es un recurso que permite dar cuenta de la naturaleza fragmentada, de la tensión y en ocasiones hasta de la incoherencia enfrentada a la idea de objetividad y neutralidad (SHARMA y GUPTA, 2006, p. 13).

Resulta interesante reparar en la propuesta de Mitchell acerca de analizar el Estado como un efecto estructural. Esto es, estudiarlo no como una estructura real, sino como el poderoso y aparentemente efecto metafísico de las prácticas que hace que tal estructura parezca existir. Las prácticas son las que en realidad producen el efecto de que el Estado parezca una entidad estructural sobre-impuesta sobre todas las demás prácticas sociales. Lo que llamamos Estado, es en definitiva la suma de esos efectos estructurales.

Latitude, Vol.2, nº 1, pp. 06-25, 2008. 
El Estado es una idea, o en términos de Mitchell un efecto, producido por la distribución organizada de tareas y roles, la coordinación del control, la combinación jerarquizada de elementos y su repetición. Todas estas son prácticas particulares. El orden y la coordinación de los procesos crean el efecto de un aparato diferente de las personas cuya "estructura" ordena, contiene y controla. El efecto del Estado construye un mundo que pretende ser algo distinto a un complejo conjunto de prácticas sociales.

El centramiento en las prácticas como modos a través de los cuales el Estado comienza a ser, es una decisión metodológica importante que abre un amplio terreno de lugares y textos a través de los cuales el Estado puede ser antropológicamente estudiado. Pensar cómo los Estados se constituyen culturalmente, cómo se sustancian en la vida de las personas y en las consecuencias sociopolíticas y cotidianas de estas construcciones, significa movernos más allá del macro nivel institucional de análisis del Estado para mirar en las prácticas. El estudio de estos aspectos nos lleva entender de otra manera el límite entre el Estado y el no Estado. A saber cómo el Estado es reproducido y desafiado como una entidad verticalmente establecida y cómo las inequidades de poder se diseñan y refuerzan a través de las prácticas e interacciones. Las prácticas políticas exceden el ámbito propio del sistema estatal institucional.

\section{Aspectos simbólicos}

Junto a las prácticas el Estado también es una idea. Nuevamente y al igual que con las prácticas es a través las formas de pensar el Estado que la autoridad estatal se recrea. Los Estados son -además de las prácticas y las instituciones, de los procedimientos- también las formas en cómo los símbolos del Estado son refundidos y recreados imaginativamente por los pueblos y las comunidades, en su práctica plena de significados, construcciones de cartografías creativas que definen espacios en el tiempo y lugares en la historia (Dube, 2001 p. 16).

Las relaciones internas y externas de las instituciones políticas y de gobierno, y éstas pueden ser estudiadas efectivamente sin postular la realidad del Estado. El conjunto palpable de prácticas y estructuras institucionales centradas en el gobierno. $Y$ sus fuentes, estructuras, y variaciones pueden ser examinadas de manera empírica.

La idea del Estado es aquello que le da las prácticas un sentido de unidad, y hace posible que detrás de cada funcionario de gobierno, de cada sello, de cada edificio público, veamos al Estado. La idea del Estado es proyectada y creída en diferentes sociedades en diferentes tiempos. Y sus modos, efectos y variaciones también son susceptibles de investigación. El Estado es real e ilusorio al mismo tiempo, o más bien, práctico y simbólico. Las respuestas no pueden ser encontradas tratando de separar las formas materiales del Estado de las formas ideológicas. O lo real de lo ilusorio. La

Latitude, Vol.2, nº1, pp. 06-25, 2008. 
idea del Estado y el sistema Estado son mejor entendidos como dos aspectos de un mismo proceso. El fenómeno que llamamos Estado, emerge de técnicas que permiten a las prácticas materiales cotidianas tomar la apariencia de una forma abstracta y no material. La tarea de una teoría del Estado no es clarificar la distinción sino profundizarla (ABRAMS, 2006, p. 170).

Es necesario estudiar al mismo tiempo la imagen poderosa de una organización claramente arraigada y unificada que puede ser nombrada en singular, como si fuera un sólo actor pensando y actuando de una sola manera en el gobierno de un territorio claramente definido y las prácticas de una variedad de partes o fragmentos, con límites no muy definidos entre ellos y otros grupos dentro y fuera de los límites estatales y que establecen conjuntos de reglas que pueden entrar en conflicto con las "oficiales" (MIGDAL, 2001). Una perspectiva antropológica nos permite poner especial atención en la constitución cultural del Estado, esto es, en cómo la gente percibe al Estado, como esos entendimientos se forman por ubicaciones particulares y se encuentran con procesos estatales y oficiales, y cómo el Estado se manifiesta en la vida de las personas (SHARMA y GUPTA, 2006, p. 11). El análisis de estos procesos culturales a través de los cuales el Estado es instanciado y experimentado también permite ver que la ilusión de la cohesión y unidad creada por el Estado siempre es contestada y frágil, y que es resultado de un proceso hegemónico que no debería ser dado por hecho.

Los efectos conflictivos que el Estado produce por la compleja dialéctica entre prácticas y representaciones rompen la hegemonía y la singularidad del Estado, y resalta las contradicciones.

La mirada sobre el Estado que elabora la antropología del Estado -un Estado intersticial que se (re) constituye a partir de modificaciones en sus rasgos estructuraleslleva a poner especial atención en cómo algunos actores perciben al Estado, cómo esta idea del Estado se manifiesta en la vida de las personas que trabajan en sus instituciones, cómo esas percepciones se corresponden con ubicaciones particulares dentro y fuera del Estado, cómo se enmarcan en procesos institucionales. El análisis de estos procesos culturales a través de los cuales el Estado es instanciado y experimentado permite ver que la cohesión y unidad es una ilusión creada por los actores estatales mismos, y que por el contrario lo que emerge es una idea disputada y frágil en tanto es el resultado de un proceso de luchas de sentido que no debería ser dado por hecho.

La focalización en las prácticas de Estado y las representaciones cotidianas como modos a través de los cuales se constituye una definición de Estado, es una decisión metodológica fundamental porque abre un amplio terreno de lugares y textos a través de los cuales repensar el concepto. Pensar cómo los Estados son constituidos culturalmente, cómo se sustancian en la vida de las personas y en las consecuencias sociopolíticas y cotidianas de estas construcciones, significa movernos más allá del nivel institucional de análisis del Estado para atender las prácticas sociales y

Latitude, Vol.2, nº 1, pp. 06-25, 2008. 
burocráticas (SHARMA y GUPTA, 2006 p. 27). Las prácticas así como las imágenes del Estado nos muestran un panorama en el que el límite entre el Estado y el no Estado es flexible y no siempre claro, la imagen es dinámica, heterogénea, contestada.

\section{Perspectivas}

Recapitulando podemos decir que comenzamos este documento señalando la necesidad de revisar las maneras así como los instrumentos conceptuales y analíticos que han prevalecido en el campo de estudio del Estado. Esta necesidad deriva de las transformaciones acontecidas en el campo de la política estatal y que día a día confirmamos. Las nuevas modalidades que adquiere el gobierno del Estado no pueden ser estudiadas en profundidad por las maneras tradicionales: éstas ensombrecen muchos e importantes aspectos. Nuestro esfuerzo se orientó a mostrar algunas líneas por donde debería transitar el estudio del Estado.

Quisimos desentendernos de una tradicional manera de entender al Estado como un sistema institucional lógico, coherente y homogéneo, y atender en cambio el estudio de los actores y de las lógicas de gobierno en múltiples niveles, sus prácticas y representaciones para encontrar los intersticios, las ambigüedades y contradicciones del Estado. No pretendemos mediante un énfasis de lo no- estatal, descuidar la importancia que tiene el Estado para el análisis de los procesos sociales. No queremos plantear un enfoque pos estatal, si por esto se entiende un abandono de la importancia del Estado como concepto. Este enfoque sólo sería post estatal en un sentido ortodoxo del mismo, en el sentido que ha sido trabajado por gran parte del análisis sociopolítico. El Estado no desaparece en estos enfoques sino que emerge reconfigurado conceptualmente. No se elimina del análisis. Por el contrario, es reubicado en una más amplia red de conceptos que tendría varias ventajas para entender al Estado hoy. Una de las potencialidades que advertimos en este enfoque es que no invisibiliza, ni minimiza la negociación, interacción y resistencia que sucede en cada sociedad entre los múltiples actores con poder. Por el contrario, no sólo echa luz sobre ellos, sino que los posiciona en un lugar central del análisis.

La antropología del Estado y el enfoque de la gubernamentalidad no son lo mismo, pero comparten este supuesto. La gubernamentalidad estaría de acuerdo en abandonar en parte el concepto de Estado para ver en cambio las lógicas de poder más allá del Estado, y considerar a este último como una de varias fuentes organizadas de poder. La antropología del Estado, en cambio, sugiere ver más allá del Estado en otro sentido, en el sentido de ir a buscarlo en ámbitos no convencionales, en lugares en los que nunca se había pensado existieran formas y prácticas de Estado. A pesar de sus diferencias, ambos enfoques -resituando la mirada del Estado, quitándolo del pedestal en el que había sido colocado- aportan en su redefinición.

Latitude, Vol.2, nº 1, pp. 06-25, 2008. 
Creemos que el enfoque reviste la suficiente ductilidad para aprehender las múltiples y diversas configuraciones del poder político propias de las sociedades políticas actuales. Esas nuevas expresiones de las sociedades políticas que comenzamos señalando en el inicio de este artículo constituyen la realidad del acontecer de los Estados hoy, al menos en nuestros países latinoamericanos. La opción que aquí presentamos por volver a pensar y poner a discusión la base analítico-conceptual de la definición del Estado es sin duda una más dentro de la lista de esfuerzos por encontrar nuevas versiones de conceptos que expliquen más y mejor la realidad política. Pero la que aquí presentamos revisten una particularidad, en la cual creemos yace su potencialidad: tanto la antropología del Estado como los estudios de la gubernamentalidad, redefinen la noción de Estado ampliando y extendiendo la base analítica, a diferencia de otros desarrollos que lo hacen adjetivando al Estado como fallido, anómico, débil, y en este sentido _además de que parecieran condenar las realidades a esos estados_ reproducen la mirada estática de cual queremos desentendernos.

\section{Bibliografia}

ABRAMS, Philip. "Notes on the difficulty of studying the state". In: SHARMA y GUPTA (Eds.). The anthropology of the state. A reader. Gran Bretaña: Blackwell, 2006.

BHASKAR, Roy. The possibility of naturalism. Nueva York: Humanities Press, 1979.

BURCHELL, Graham. Peculiar interest: civil society and governing: The system of natural liberty. In: Graham Burchell, Gordon C. y Miller P. (Eds.). The Foucault effect. Chicago: The University of Chicago Press, 1991.

CURTIS, Bruce. Taking the State Back Out: Rose and Miller on Political Power. The British Journal of Sociology. Vol. 46, nº 4, pp. 575-589, Diciembre, 1995.

DE MARINIS, Pablo. Gobierno, gubernamentalidad, Foucault y los anglofoucaultianos (Un ensayo sobre la racionalidad política del neoliberalismo). In: García Selgas, Fernando y Ramos Torre Ramón, (Comps.). Retos Actuales de la Teoría Social: Globalidad, Reflexividad y Riesgo. Madrid: Centro de Investigaciones Sociológicas, 1999.

DUBE, Saurabh. Sujetos subalternos. Capítulos de una historia antropológica, México: El Colegio de México, 2001.

EVANS, Peter et al. Bringing the State Back in. Cambridge: Cambridge University Press, 1985.

ESCALANTE, Fernando. Baile de máscaras. Conjeturas sobre el Estado en América Latina. Nueva Sociedad. nº 210. Buenos Aires: Argentina, julio-agosto, 2007.

Latitude, Vol.2, nº 1, pp. 06-25, 2008. 
FOUCAULT, Michel. About the beginning of the hermeneutics of the self (Transcription of two lectures in Dartmouth on 17 and 24 November 1980, ed. M. Blasius). Political Theory. Vol. 21, n², pp. 198-227, 1993.

GEERTZ, Clifford. What is a state if not a sovereign? Reflections on politics on complicated places. Current Anthropology. Vol. 45, $\mathrm{n}^{\circ} 5,2004$.

GIDDENS, Anthony. Central problems in social theory: action, structure and contradiction in social analysis. Berkeley: University of California Press, 1979.

GRINBERG, Silvia. Gubernamentalidad: estudios y perspectivas. Revista Argentina de Sociología. Vol.5, nº 8. Buenos Aires, mayo/junio, 2007.

MIGDAL, Joel. State in society. Studying how states and societies transform and constitute one another.NuevaYork.: Cambridge University Press,2007.

O’MALLEY, Pat. Riesgo, neoliberalismo y justicia penal. Buenos Aires: Editorial Ad Hoc, 2006.

ROSE, Nikolas. Powers of freedom. Reframing political thought. Cambridge: Cambridge University Press, 1999.

. Governing liberal "advanced" democracies. In: SHARMA y GUPTA (Eds.). The anthropology of the state. A reader.Gran Bretaña: Blackwell, 2006.

ROSE, Nikolas et ali. Governmentality. Law \& Society, Annual Review, nº 2, p. 83, 2006.

ROSE, Nikolas. y PETER, Miller. Political Power beyond the State: Problematics of Government. The British Journal of Sociology, Vol. 43, nº 2, 1992.

SHARMA, Aradhana. y AKHIL, Gupta. Introduction: rethinking theories of the state in an age of globalization. In: SHARMA y GUPTA (Eds.). The anthropology of the state. A reader. Gran Bretaña: Blackwell, 2006.

STEINMETZ, George. Introduction: Culture and the state. In: STEINMETZ, Georg (Eds.). State/Culture. State-formation after the cultural turn. Estados Unidos: Cornell University Press, 1999.

TIMOTHY, Mitchell. Society, economy and the state effect. In: SHARMA y GUPTA (Eds.). The anthropology of the state. A reader. Gran Bretaña: Blackwell, 2006.

TROUILLOT, Michel-Rolph. The anthropology of the state in the age of globalization. Current anthropology. VoL.42, $\mathrm{n}^{\mathrm{o}}$ 1, Febrero, 2001.

Latitude, Vol.2, nº 1, pp. 06-25, 2008. 